\title{
Level of knowledge and perceptions of basic life support among under graduate medical students in tertiary care teaching hospital in Central India. A questionnaire based study
}

\author{
Uike S. ${ }^{1}$, Netty L. ${ }^{*}$
}

\author{
DOI: https://doi.org/10.17511/ijphr.2018.i2.03
}

\footnotetext{
${ }^{1}$ Satyendra Uike, Associate Professor, Department of Anesthesiology, Bundelkhand Medical College, Sagar, Madhya Pradesh, India.

2* Lokesh Netty, Assistant Professor, Department of Anesthesiology, Bundelkhand Medical College, Sagar, Madhya Pradesh, India.
}

\begin{abstract}
Introduction: Knowledge of basic life support (BLS) is essential for medical personnel and for every person to save life in life threatening conditions. Well designed certified BLS /cardiopulmonary resuscitation (CPR) training workshop at a regular interval and compulsory training should be made as a part of present academic medical curriculum. Aim: To assess the present status knowledge and perception of CPR among clinical undergraduate medical students, a cross section questionnaire base study conducted to develop an efficacious training program in their academic curriculum. Results: We observed that the mean knowledge score of all students was less than $50 \%$. Out of all, the mean knowledge score of female students was statistically significantly higher than the mean knowledge of male students, whereas intern students had higher knowledge score as compared to final and pre-final medical students. All the students possessed a positive perception of BLS. Conclusion: We concluded that knowledge about BLS among clinical undergraduates was below average, however, they have positive perceptions towards BLS. It can be improved by conducting well designed certified BLS /CPR training cum workshop.
\end{abstract}

Keywords: Basic life support, Knowledge, Perception, Medical students

Corresponding Author

Lokesh Netty, Assistant Professor, Department of Anesthesiology, Bundelkhand Medical College, Sagar, Madhya Pradesh, India.

Email: lokeshnettygmc@gmail.com
How to Cite this Article

Uike S, Netty L. Level of knowledge and perceptions of basic life support among under graduate medical students in tertiary care teaching hospital in Central India. A questionnaire based study. Public Health Rev Int J Public Health Res. 2018;5(2):65-70. Available From

https://publichealth.medresearch.in/index.php/ijphr/ article/view/84
To Browse

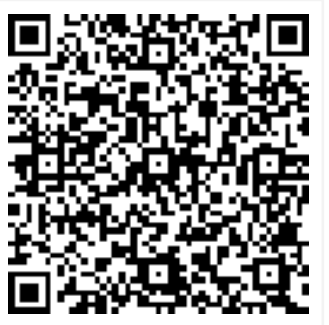

Manuscript Received 2018-03-26

Conflict of Interest No

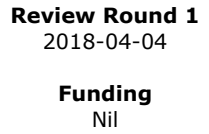

Review Round 1

$\mathrm{Nil}$

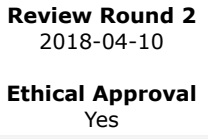

Review Round 3

Accepted 2018-04-16

Plagiarism $\mathbf{X}$-checker $4 \%$

Note

(c) 2018 by Satyendra Uike, Lokesh Netty and Published by Siddharth Health Research and Social Welfare Society. This is an Open Access article licensed under a Creative Commons Attribution 4.0 International License https://creativecommons.org/licenses/by/4.0/ unported [CC BY 4.0]. 


\section{Introduction}

Cardiopulmonary resuscitation (CPR) in basic life support (BLS) is an emergency medical procedure performed to restore blood flow (circulation) and breathing. The goal of CPR is to provide oxygen quickly to the brain, heart, lungs, and other organs until normal function of the heart and lung is restored.

CPR can help prevent brain damage and death in a victim [1-3]. Cardiopulmonary resuscitation is a technique of basic life support for the purpose of oxygenation to heart, lungs and brain until and unless the appropriate medical treatment can come and restore the normal cardiopulmonary function.

In witnessed cardiac arrest, early recognition with early efficacious cardiopulmonary resuscitation and rapid defibrillation in shockable rhythm will result in successful resuscitation outcomes and with increased chances of survival of the victims $[4,5]$.

The success rate of CPR ranging widely from $5 \%$ to $10 \%$ is based on many factors such as causes of cardiac or respiratory arrest and underlying health conditions of victims, time elapse between an arrest and CPR and effective techniques for CPR $[6,7]$.

According to American Heart Association, CPR should start within 10 seconds of recognition of cardiac arrest [8]. An appropriate response in an emergency situation depends on good technical knowledge, which decides the patient's outcome [9].

Therefore, teaching medical students and training doctors in emergency care is essential. All healthcare personnel are anticipated to be up-skilled in basic life support whichis an easy and effective technique ina cardiac arrest situation, at any time in the courseof their medical profession.

Previous reports on CPR showed that both the medical students and the junior medical staff were lacking in the essential BLS skills [10-12]. Poor knowledge of BLS among medical students augured a serious pitfall to victimsand to community health.

The aim of this study is to explore the level of knowledge and perceptions of CPR among clinical medical students in the bundelkhand medical college, with the aim of providing a model for incorporating CPR training into the medical college curriculum.

\section{Materials and Method}

This questionnaire based cross-sectional study was conducted among 234 clinical undergraduate medical students of the Bundelkhand Medical College, Sagar during the academic year in September-October 2017, after obtaining ethical permission from the institute.

After explaining the purpose of the study, questionnaires were distributed among interns and final year and pre-final year undergraduate medical students of the institution, who had given a verbal consent to be part of the study.

A semi structured, anonymous questionnaire was designed to assess their (1) Demographic data and qualification, (2) knowledge and Perceptions of participants regarding BLS (15 multiple choice questions were prepared as per Guidelines for CPR 2015 by American Heart Association) and was prepared in English language.

The knowledge score for every participant was calculated, where maximum score possible were 15 and 0 was the minimum score. More the score, the better the knowledge regarding BLS (Questionnaire).

The data were compiled, tabulated, and statistically analyzed using an ANOVA test (to compare knowledge score of students at various academic levels) and Student's t-test (to compare knowledge score of males and females). A critical $P=0.05$ was considered statistically significant.

\section{Results}

This study included 234 questionnaires distributed among the clinical undergraduate medical students. Out of all, $96(41.02 \%)$ were males and 138 $(58.97 \%)$ were females with age group between 22 to 27 years.

This study group composed of 68 (29.05\%) prefinalyear students, 104 (44.4\%) final year students, and $62(26.49 \%)$ were interns. The data listed in Table 1 shows that the mean knowledge score of males (7.29) was significantly lower than the mean knowledge score of females (8.34) $(P=0.02)$.

When evaluated on individual basis, the lowest score obtained by male students was 2 out of a total score of 15 and the highest score being 12 . Where as, the lowest score of 3 and the highest score of 14 were fetched by female students. 
Table-1: Comparison of the knowledge score in relation to different characteristics of the participants

\begin{tabular}{|l|l|l|l|l|l|l|l|}
\hline \multicolumn{2}{|c|}{ Variable } & Number of students $(\mathrm{n}=\mathbf{2 3 4})$ & Highest score & Lowest score & Mean(SD) score & F/t-value & p-value \\
\hline \multirow{3}{*}{ Gender } & Male & 96 & 12 & 2 & $7.29(3.4)$ & 2.133 & $0.034^{*}$ \\
\cline { 2 - 8 } & Female & 138 & 14 & 3 & $8.34(3.9)$ & & \\
\hline Academic & Pre-final year & 68 & 2 & 11 & $4.0(2)$. & 32.4 & $<0.00^{* *}$ \\
\cline { 2 - 6 } & Final year & 104 & 2 & 13 & $5.04(2.5)$ & & \\
\cline { 2 - 6 } & Interns & 62 & 3 & 14 & $7.80(3.6)$ & & \\
\hline
\end{tabular}

*Unpair t-test, **Anova test

A highly statistically significant difference was detected among the three different academic levels (ANOVA test, $P<0.0$ ). The analysis showed that the mean score of the interns was significantly higher than pre-final and final year students.

As shown in Table 2, theabbreviation BLS and EMSstands for was correctly answered by most of the students i.e. $79.0 \%$ and $43.7 \%$ respectively. However, $19.5 \%$ knew the abbreviation AED as automated external defibrillator.

The majority of the students would ask for help if they foundan unconscious person at roadside. Only $32.2 \%$ students knew when to activate emergency response system after immediate recognition of cardiac arrest. Most of the students were aware to palpate carotid artery in the unconscious person, where most of them were imprecise to tell the minimum 5 second and maximum 10 seconds is theduration to assess the circulation. Only $27.4 \%$ and $50 \%$ students were aware of site and rate of chest compression although $49.5 \%$ of them failed to tellthe correct depth of chest compression.

Among 234 students, only 103 (43.7\%) students correctly answered the technique to give breaths in infants. Most $(43.7 \%)$ of them knew the compression ventilation ratio is $30: 2$. The preferred sequence is C-A-Bin BLS was correctly answered by $40.0 \%$. Neverthe less, $54.2 \%$ students knew the critical characteristics of high quality CPR, but $74.2 \%$ among them fail to tell when to give abdominal thrust in choking person.

Table-2: Knowledge based questionnaire analysis BLS among undergraduate medical students

\begin{tabular}{|l|l|l|l|}
\hline $\begin{array}{r}\text { Question } \\
\text { number }\end{array}$ & \multicolumn{1}{|c|}{$\begin{array}{c}\text { Correct response } \\
(\%)\end{array}$} & $\begin{array}{r}\text { Wrong response } \\
(\%)\end{array}$ & \multicolumn{1}{|c|}{$\begin{array}{c}\text { Don'tknow } \\
(\%)\end{array}$} \\
\hline Question 1 & $185(79.05 \%)$ & $43(18.37 \%)$ & $6(2.56 \%)$ \\
\hline Question 2 & $134(57.26 \%)$ & $91(38.88 \%)$ & $9(3.84 \%)$ \\
\hline Question 3 & $76(32.6 \%)$ & $136(57.4 \%)$ & $22(10.0 \%)$ \\
\hline
\end{tabular}

\begin{tabular}{|l|l|l|l|}
\hline Question 4 & $168(71.6 \%)$ & $57(24.2 \%)$ & $9(4.2 \%)$ \\
\hline Question 5 & $52(22.26 \%)$ & $161(68.9 \%)$ & $20(8.9 \%)$ \\
\hline Question 6 & $65(27.4 \%)$ & $135(57.9 \%)$ & $34(14.7 \%)$ \\
\hline Question 7 & $117(50.0 \%)$ & $64(27.4 \%)$ & $53(22.6 \%)$ \\
\hline Question 8 & $52(22.2 \%)$ & $181(77.4 \%)$ & $1(0.5 \%)$ \\
\hline Question 9 & $93(40.0 \%)$ & $116(49.5 \%)$ & $25(10.5 \%)$ \\
\hline Question 10 & $103(43.7 \%)$ & $81(34.7 \%)$ & $50(21.6 \%)$ \\
\hline Question 11 & $107(45.8 \%)$ & $113(47.9 \%)$ & $14(6.3 \%)$ \\
\hline Question 12 & $45(19.5 \%)$ & $168(71.6 \%)$ & $21(8.9 \%)$ \\
\hline Question 13 & $93(40.0 \%)$ & $89(37.9 \%)$ & $52(22.1 \%)$ \\
\hline Question 14 & $46(19.5 \%)$ & $173(74.2 \%)$ & $15(6.3 \%)$ \\
\hline Question 15 & $126(54.2 \%)$ & $77(32.6 \%)$ & $31(13.2 \%)$ \\
\hline
\end{tabular}

As shown in Table 3, only 47 respondents had previously attended BLS workshop. Of 234 study participants, only $14(\%)$ had done/seen CPR on patients while remaining $220(\%)$ had never witnessed CPR. Despite the lack of awareness regarding BLS, only 39 participants were confident to perform CPR in comparison to 195 students (78.4\%) who had no such reluctance. The cause for disinclination reported was the lack of knowledge regarding the field. Furthermore, they were of perspective that the BLS training must be included in the academic curriculum and there should be regular BLS awareness training for general populations.

Table No-3: Perception of BLS among students

\begin{tabular}{|l|l|l|l|}
\hline \multicolumn{1}{|c|}{ Variable } & Yes & No & Neutral \\
\hline Assured of performing CPR independently & 39 & 195 & 19 \\
\hline BLS training should be included in curriculum & 231 & 1 & 2 \\
\hline BLS Training for general public & 291 & 9 & 6 \\
\hline Previous BLS workshop attended & 47 & 187 & \\
\hline Practically done /seen CPR on patients & 14 & 220 & \\
\hline
\end{tabular}

\section{Discussion}

The knowledge of BLS and practice of simple CPR techniques is a major determinant in the success of resuscitation and plays a vital role in the survival of patients in critical emergency situations, till experienced medical help arrives [13]. 
Freshly qualified doctors must have an adequate knowledge about recognition of cardiac arrest and technically skilled in performing an effective CPR. This study showed a markedly inadequate knowledge of CPR among clinical medical students, as the majority of the students was scoring below the average of $50 \%$.

The low percentage observed in this study is probably because formal CPR training and retraining is not strictly incorporated into the medical curriculum. Arsatiet al found that the common cause for the lack of the knowledge among students was lack of training and updates in an undergraduate program [14]. A similar deficient knowledge of CPR was observed in other studies among medical students, healthcare professionals [10-12].

In our study, the participants with higher academic level had relatively higher knowledge scores in comparison to those with lower academic level, this may be due to more exposure to clinical training, although all the students had an insufficient knowledge which accentuates the importance of regular repetition of CPR training.

In thepresent study, we found that $16.66 \%$ of the students were assured of performing CPR independently whereas most of the undergraduates were reluctant to performing resuscitation, may be due to the lack of knowledge regarding BLS. Although Roshanaet alobserved, $82.6 \%$ were not reluctant to perform CPR when needed, and 21 (17.4\%) were reluctant to perform resuscitation.

The most commonly cited anxiety for the performance of resuscitation was fear of being ineffective $(8.2 \%)$ which was followed by fear of further harm to the victim $(5.7 \%)$ [15]. Whereas Alotaibi et alnoticed, about two-thirds of the respondents were reluctant to perform CPR[16].

Our study entrenched that only $20.08 \%$ undergraduate student who had previously attended BLS workshop, though $5.98 \%$ of participants had previously done/seen CPR on patients. In comparison to study by Alotaibi et alfound that almost all the participants (99.1\%) had attended previous BLS workshops but most of them (86.8\%) had not been involved in any patient resuscitation experience [16].

In our study, intern students showed a very positive attitude towards BLS as most of them had attended the workshop on BLS, but they were not confident to perform in a critical situation.
Almost all students were willing to attend further workshops and additional training programs on BLS/CPR, which coincides with the need for continuing education courses. Ideally, everyone should know about BLS and CPR, and its awareness to medical personnel should be a prerequisite for advancing into higher levels of training.

This study emphasized the cognitive approach to the general perception and skills of Basic Life Support, early recognition of cardiac arrest. It is now essential to standardize trainingin advanced life support and make it a mandatory component of all medical, nursing and Para-medical school, undergraduate curricula [17]. It is also equally important that teachers, school children, public and all lay person from the community to be taught the facts of basic life support and first aid. It is recommended that theoretical knowledge of CPR should be part of the curriculum in high school and medical colleges, workshops on a regular basis should be conducted for medical students to teach the practical aspects of CPR on dummies.

\section{Conclusion}

From the present study we concluded that knowledge about BLS among clinical undergraduates was below average, however they have positive perceptions towards BLS. It can be improved by conducting well designed certified BLS /CPR training workshop at a regular interval and compulsory training should be made as a part of academic medical curriculum. Not only medical health providers but also the general public should be informed and encouraged in participating to gain knowledge by campaigns and media forums about BLS/CPR.

\section{Acknowledgments}

We thank the College, Institutional Ethics Committee and the Dean, who permitted us to conduct the study. We also thank the students, without their participation this study would not have been possible.

\section{Reference}

01. Varon J, Marik PE, Fromm RE. Cardiopulmonary resuscitation- a review for clinicians. Resuscitation. 1998;36;133-145.

[Crossref] 
02. Sasson C, Rogers MA, Dahl J, Kellermann AL. Predictors of survival from out-of hospital cardiac arrest- a systematic review and metaanalysis. Circ Car-diovasc Qual Outcomes. 2010 Jan;3(1)63-81.

doi:10.1161/CIRCOUTCOMES.109.889576. Epub 2009 Nov 10 [Crossref]

03. Jiang L, Zhang J. Mechanical cardio pulmonary resuscitation for patients with cardiac arrest. World Journal of Emergency Medicine. $2011 ; 2(3) 165-168$.

doi:10.5847/wjem.j.1920-8642.2011.03.001

[Crossref]

04. Perkins GD, Brace S, Gates S. Mechanical chestcompression devices- current and future roles. Curr Opin Crit Care. 2010 Jun;16(3)203-10. doi: $10.1097 /$ MCC.0b013e328339cf59 [Crossref]

05. Jacobs I, Nadkarni V, Bahr J, Berg RA, Billi JE, Bossaert $L$, et al. Cardiac arrest and cardio pulmonary resuscitation outcome reportsUpdate and simplification of the Utstein templates for resuscitation registries-A statement for healthcare professionals from a task force of the international liaison committee on resuscitation (American Heart Association, European Resuscitation Council, Australian Resuscitation Council, New Zealand Resuscitation Council, Heart and Stroke Foundation of Canada, Inter American Heart Foundation, Resuscitation Council of Southern Africa). Resuscitation. 2004;63;233-49.

[Crossref]

06. Axelsson C, Karlsson T, Axelsson AB, Herlitz J. Mechanical active compression-decompression cardio pulmonary resuscitation (ACD-CPR) versus manual $C P R$ according to pressure of end tidal carbon dioxide (PET CO2) during CPR in out-of-hospital cardiac arrest (OHCA). Resuscitation. 2009 Oct;80(10)1099-103.

doi: 10.1016/j.resuscitation.2009.08.006. Epub 2009 Aug 28 [Crossref]

07. Moreno RP, Vassallo JC, Sáenz SS, Blanco AC, Allende $\mathrm{D}$, Araguas $\mathrm{JL}$, et al. Cardiopulmonary resuscitation in nine pediatric intensive care units of the Argentine Republic. Arch Argent Pediatr. 2010 Jun;108(3)216-25.

doi: $10.1590 /$ S0325-00752010000300007 [Crossref]
08. American Heart Association- BLS for Health care Providers-Students manual. Part one, $\mathrm{p}-3$ accessed on 12/12/2013. .

doi: $10.1590 /$ S0325-00752010000300007 [Crossref] [PubMed] [Google Scholar] [Crossref]

09. Ruesseler M, Weinlich M. Simulation training improves ability to manage medical emergencies. Emerg Med J. 2010 Oct;27(10)734-8.

doi: $10.1136 /$ emj.2009.074518 [Crossref]

10. Harsha Kumar HN, Upadhya PS, Ashok PS, Chowdari GA, Niranjan GM, Dinesh B. A crosssectional study on awareness and perception about basic life support/ cardio pulmonary resuscitation among undergraduate medical students from coastal South India. Int J Med Public Health. 2013;3;146-150.

[Crossref]

11. Chandrasekaran S, Kumar S, Bhat SA et al. "Awareness of basic life support among medical, dental, nursing students \& doctors". Indian J Anaesth. 2010;54;121-6.

[Crossref]

12. PS Phillips, JP Nolan. "Training in basic and advanced life support in $\mathrm{U} \mathrm{K}$ medical schoolsQuestionnaire survey". BMJ. 2001 July 7;323(7303)22-23.

[Crossref]

13. Steen PA, Kramer-Johansen J. Improving cardiopulmonary resuscitation quality to ensure survival. Curr Opin Crit Care. 2008 Jun; 14(3)299-304.

doi: $10.1097 /$ MCC.0b013e3282f $827 \mathrm{~d} 3$ [Crossref]

14. Arsati F, Montalli VA, Flório FM, Ramacciato JC, da Cunha FL, Cecanho R, et al. Brazilian dentists' attitudes about medical emergencies during dental treatment. J Dent Educ. 2010; 74;661-6.

[Crossref]

15. Roshana S, KH B, RM P, MW S. Basic life support- knowledge and attitude of medical/ paramedical professionals. World Journal of Emergency Medicine. 2012;3(2)141-145.

doi: $\quad 10.5847 /$ wjem.j.issn.1920-8642.2012.02.011 [Crossref] 
16. Alotaibi OA, Alamri F, Almufleh L, Alsougi W. Basic life support- Knowledge and attitude among dental students and staff in the College of Dentistry, King Saud University. Saudi J Dent Res. $2016 ; 7 ; 51-6$.

doi: $10.1016 /$ j.sjdr.2015.06.001 [Crossref]

17. Steen PA, Kramer-Johansen J. Improving cardiopulmonary resuscitation quality to ensure survival. Curr Opin Crit Care. 2008 Jun;14(3)299-304.

doi: 10. 1097/MCC.0b013e3282f827d3 [Crossref]

\section{Questionnaire}

The questionnaire that was distributed among students: Survey about knowledge regarding "basic life support" fill in the following details

Demographics: *Gender \& Age * Your Academic level: 3rd year /final year /intern student. Ticks mark the correct answer. Leave it blank in case you don't know the answer.

01. What is the abbreviation "BLS" stands for?

(A) Basic Life Support (b) Best Life Services (c) Basic Lung Support (d) Basic Life Standards

02. If an adult person found unresponsive on the road. What will be your first step?

(A) Maintain airway (b) Start chest compression (c) Ask for help (d) Start giving breathings

03. If an adult person after accident is not responding to you even after your verbal command and shaking at him, what will be your immediate next step?

(A) Rapid defibrillation (b) Immediate recognition of cardiac arrest andactivation of emergency response system (c) Put himin recovery position (d) Observe

04. Where should you check for a Pulse in unresponsive adult?

(A) Carotid Artery (b) Brachial Artery (c) Femoral Artery (d) Radial Artery

05. How much time you will try to feel for pulse before moving to start chest compressions?

(A) Minimum 5 sec\&Maximum10seconds

(b) Minimum $10 \mathrm{sec} \&$ Maximum15 seconds

(c) Minimum 15 seconds \& Maximum 20 seconds
(D) any of the above

06. What is the location for chest compression in adults?

(A) Right side of the chest (b) Left side of the chest

(c) Centre of the chest on breast bone (d) anywhere on chest region.

07. Rate of chest compression in adult and Children during CPR?

(A) At least $120 / \mathrm{min}$ (b) At least $100 / \mathrm{min}$ (c) At least $90 / \mathrm{min}$ (d) At least $80 / \mathrm{min}$

08. Technique to give breaths in infants?

(A) Mouth-to-mouth only (b) Mouth-to-mouth andnose (c) Mouth-to-nose only (d) Mouth-to-mouth without nose pinched

09. What is Depth of compression in adults during CPR?

(A) At least 2 inches (b) 21/2- 3 inches (c) Less than 2 inches (d) According to your comfortable level

10. During CPR, the Compression-Ventilation ratio in adult?

(A) $30: 1$ (b) $15: 2$ (c) $30: 2$ (d) $15: 1$

11. Abbreviation EMS stands for?

(A) Effective Medical Support (b) Emergency Management Services (c) Emergency Medical Services

(D) External Medical Services

12. Abbreviation "AED "stands for?

(A) Automated External Defibrillator (b) Automated Electrical Defibrillator (c) Advanced Electrical Defibrillator (d) Advanced External Defibrillator

13. The preferred sequence of BLS is

(A) A-B-C (b) A-C-B (c) C-A-B (A: airway, B: breathing, $\mathrm{C}$ : compression)

14. If any person while eating food, suddenly starts expressing symptoms of choking and is Confirmed by taking to him, what will be your first response on the spot?

(A) Give back blows (b) Give chest compression (c) Give abdominal thrusts (d) any of the above 
15. Characteristics of High-Quality CPR, includes which of the following?

(A) Minimize Interruptions (b) Push Hard and Fast

(c) Starting Chest Compressions within 10 Seconds

(d) All of The Above 